Research Article

\title{
Safety of deferasirox as an oral iron chelator in thalassemic children
}

\author{
Shikha Jaiswal $^{1 *}$, Rajesh Hishikar ${ }^{1}$, Basant Maheshwari ${ }^{1}$, Onkar Khandwal ${ }^{2}$, Raka Sheohare ${ }^{3}$
}

${ }^{1}$ Department of Pharmacology,

Pt. Jawaharlal Nehru Memorial

Medical College Raipur

Chhatisgarh, India,

${ }^{2}$ Department of Pediatrics, Pt.

Jawaharlal Nehru Memorial

Medical College Raipur,

Chhatisgarh, India,

${ }^{3}$ Consultant cardiologist,

Lifeline Hospital, Raipur, India

Received: 30 April 2016

Revised: 15 May 2016

Accepted: 18 May 2016

\section{*Correspondence to:}

Dr. Shikha Jaiswal,

Email: dr.shikhajaiswal

@ gmail.com

Copyright: (C) the author(s), publisher and licensee Medip Academy. This is an openaccess article distributed under the terms of the Creative Commons Attribution NonCommercial License, which permits unrestricted noncommercial use, distribution, and reproduction in any medium, provided the original work is properly cited.

\begin{abstract}
Background: Thalassemia major patients require frequent blood transfusion leading to iron overload. Iron overload is characterized by excessive iron deposition and consequent injury and dysfunction of the heart, liver, anterior pituitary, pancreas, and joints. Because physiologic mechanisms to excrete iron are very limited, patients with iron overload and its complications need safe, effective therapy that is compatible with their coexisting medical conditions. Current prospective, observational study is done to assess the safety of deferasirox as an oral iron chelator, with specific reference to rise in serum creatinine level, alanine aminotransferase level (SGPT), urine albumin level in 50 multi-transfused thalassemia major children receiving deferasirox (DFX) therapy at registered thalassemia society Raipur, India.
\end{abstract}

Methods: DFX was administered in an initial dose of $20 \mathrm{mg} / \mathrm{kg} / \mathrm{day}$ and increased to a maximum of $40 \mathrm{mg} / \mathrm{kg} / \mathrm{day}$. Serum creatinine, alanine aminotransferase level (SGPT), urine albumin level were estimated in pretransfusion samples at time of registration and at 3 monthly intervals (4 times). The primary end point of the study was completion of 12 months of therapy (January 2013 to December 2013).

Results: Prior to DFX therapy the mean serum creatinine, SGPT, urine albumin of all cases were $0.4617 \mathrm{mg} / \mathrm{dl}, 20.78 \mathrm{U} / \mathrm{L}$ and nil respectively. After 12 months of DFX therapy of mean dose $38 \mathrm{mg} / \mathrm{kg} / \mathrm{day}$, the mean serum creatinine was. $0.4624 \mathrm{mg} / \mathrm{dL}$. SGPT was $20.81 \mathrm{U} / \mathrm{L}$, and urine albumin was nil.

Conclusions: Deferasirox monotherapy has a good safety profile and effectively chelates total body iron.

Keywords: Deferasirox, Iron chelation, Management, Thalassemia

\section{INTRODUCTION}

Iron chelation therapy forms an important part of treatment for patients receiving red blood cell transfusions. Iron chelation therapy is a supportive therapy for chronic anemias, such as $\beta$-thalassemia, sickle cell disease (SCD), and the myelodysplastic syndromes (MDS). Iron chelators currently available include desferoxamine, which is administered subcutaneously or intravenously, and the oral chelators deferiprone and deferasirox. ${ }^{1}$
The reports stated-standard iron chelator, desferoxamine (DFO), has a safety and efficacy profile established through many years of clinical use, but the regimen of prolonged 12 hours subcutaneous infusions, 5-7 days per week is extremely demanding and can result in poor adherence, thereby compromising efficacy and outcomes. $^{2}$

In 1999, deferiprone (Ferriprox; L1), a three times daily oral chelating agent, became licensed in Europe and other regions for the treatment of iron overload. The drug may be more effective than DFO in chelating cardiac iron. Its side effects include gastrointestinal symptoms, joint pain, 
liver dysfunction, neutropenia and agranulocytosis. ${ }^{3-5}$ Because of the risk of agranulocytosis, a weekly assessment of white blood cell counts is recommended.

Deferasirox, a convenient, once-daily oral therapy, has demonstrated good efficacy and acceptable safety in adult and pediatric patients with wide range of chronic anemias. $^{6-8}$ The long half-life of 8-16 hours provides sustained 24 hour chelation coverage, something that has previously not been achieved with a single agent. ${ }^{9,10}$ Deferasirox (DFX), approved, by FDA in year 2005 is safe, oral iron chelator. Serum creatinine, alanine aminotransferase level (SGPT), urine albumin level are convenient, non-expensive and the most widely used measure of assessing safety of deferasirox. ${ }^{11,12} \mathrm{We}$ prospectively assessed serum creatinine, alanine aminotransferase level (SGPT), urine albumin level in an enrolled group of multi-transfused thalassemia patients to evaluate the safety of DFX as an iron chelator.

\section{METHODS}

This prospective single arm study was conducted from January 2013 to December 2013 on 50 multi-transfused thalassemic patients of age 1-18 years to monitor the effect of deferasirox on kidneys and liver. This study was conducted in accordance with good clinical practice guidelines and was approved by the college ethical committee. Patient receiving multi-transfusion for thalassemia major and receiving deferasirox therapy during January 2013 to December 2013 were included in our study. Informed consent was obtained in written form from the patient's guardian recruited in our study. The nature of study was discussed with each patient's guardian in the manner they understand. Serum creatinine, alanine aminotransferase level (SGPT), urine albumin level were estimated in pre-transfused state and subsequently every 3 months basis. Serum creatinine, alanine aminotransferase level (SGPT) were determined by using biochemistry analysis photometric technique and urine albumin was determined by urine analyser (Clinitek Siemens).

Patient will receive a single dose of deferasirox at $20-25 \mathrm{mg} / \mathrm{kg} /$ day given empty stomach in the morning and further dose escalation done to a maximum of $40 \mathrm{mg} / \mathrm{kg} /$ day according to response. Dose reduction was done if any side effect was noted or if serum creatinine level increase to $33 \%$ of normal at two consecutive visits. Dose reduction done or treatment was halted for 15 days if SGPT level rise 5 times of upper limit of normal at two consecutive visits or $3+$ albuminuria starts in a normal person. The relevant data were recorded in specified proforma. The data was compiled in the formats and subjected to descriptive and statistical analysis. The primary end point of the trial was to evaluate the difference in serum creatinine, alanine aminotransferase level (SGPT), urine albumin level after 12 months of DFX therapy as compared to baseline values. Data were presented as mean \pm SD and variables analysed by one way ANOVA test for statistical significance. $\mathrm{P}<0.05$ was considered statistically significant.

\section{RESULTS}

50 patients were enrolled. 5 were lost to follow up. 45 patients completed the study. In our study, maximum affected age group of thalassemia requiring iron chelation therapy is between ages of 0-5 years (20\%), 6-10 years $(48.89 \%), \quad 11-15$ years $(24.40 \%)$ and $16-18$ years $(6.67 \%)$.

27 males $(60 \%)$ and 18 females $(40 \%)$ received regular transfusion with a mean age of $8.68 \pm 3.9$ years (3.6-17 years).

The mean serum creatinine levels at different follow-ups are given in table 1 . The mean difference in serum creatinine level after 3 months is $0.0089 \pm 0.121913$; after 6 months is $0.0111 \pm 0.030765$; p-value of after 9 months is $0.2133 \pm 0.122411$; $\mathrm{p}$-value and after 12 months is $0.00067 \pm 0.124122$.

Table 1: Time versus serum creatinine levels (mg/dl).

\begin{tabular}{|lll|l|}
\hline Groups & Mean & SD & Variance \\
\hline Base line & 0.461778 & 0.097054 & 0.009419 \\
\hline 3 months (fu 1) & 0.462667 & 0.119305 & 0.014234 \\
\hline 6 months (fu 2) & 0.462889 & 0.092996 & 0.008648 \\
\hline 9 months (fu 3) & 0.483111 & 0.107107 & 0.011472 \\
\hline 12 months (fu 4) & 0.462444 & 0.118055 & 0.013937 \\
\hline
\end{tabular}

Non significant ( $\mathrm{p}$ value 0.855 ) rise in levels of serum creatinine after one year of deferasirox therapy. Fu denotes follow up.

Table 2: Time versus serum SGPT levels (U/L).

\begin{tabular}{|llll|}
\hline Groups & Mean & SD & Variance \\
\hline Base line & 20.78 & 22.78638 & 0.009419 \\
\hline 3 months (fu 1) & 20.82 & 21.75409 & 0.014234 \\
\hline 6 months (fu 2) & 20.83 & 19.68297 & 0.008648 \\
\hline 9 months (fu 3) & 21.74 & 21.65664 & 0.011472 \\
\hline 12 months (fu 4) & 20.81 & 24.28767 & 0.013937 \\
\hline
\end{tabular}

Non significant ( $\mathrm{p}$ value 0.855 ) rise in levels of SGPT after one year of deferasirox therapy. Fu denotes follow up.

Non-significant difference in serum creatinine observed after 12 months of deferasirox therapy. P-value $=074$ $(>05)$.

Mean Difference in SGPT level after 3 months is $2.711 \pm 18.759$; after 6 months is $0.5111 \pm 11.537$; after 9 months is $1.222 \pm 11.492$ and after 12 months is 4.311 \pm 20.72 . Non-significant difference in SGPT observed after 12 months of deferasirox therapy. Pvalue $=074(>05)$.

Urine albumin was nil in all cases before, during and after 12 months of deferasirox therapy. 
$46.5 \%$ patients (21) had drug compliance of $80-98.8 \%$ and $53.2 \%$ (24) had drug compliance of $100 \%$.

\section{DISCUSSION}

Thalassemia major patients require frequent blood transfusion leading to iron overload. ${ }^{13}$ Excess iron absorption and transfusional iron intake cause iron accumulation in the liver, endocrine organs, heart, and other tissues with severe, life-threatening consequences. Iron cardiomyopathy is of particular concern, and remains the leading cause of death in patients with thalassemia major. ${ }^{14-17}$ Several serum markers can be used to follow trends in a patient's iron status over time. These include ferritin, serum iron, and non-transferrin bound iron (NTBI), as well as total iron binding capacity and transferrin saturation (TSAT). Serum ferritin is the most frequently used measure as it is inexpensive, widely available, and reliable, with extensive clinical validation in monitoring iron status.

Since regular blood transfusion is mainstay of thalassemia therapy, iron chelation therapy become mandatory when serum ferritin level crosses $1000 \mathrm{ng} / \mathrm{ml}$. Deferasirox is commonly used as oral iron chelator among various iron chelators available. Deferasirox shows significant decline in serum ferritin level and has good safety profile in thalassemic children.

Our study was done in registered thalassemia society Raipur, India. Total 50 patients were registered and followed over one year study period (January 2013 to December 2013).

In our study $60 \%$ patients were males and mean age group was found to be $8.6 \pm 3.9$ years.

Merchant $\mathrm{R}$ et al have found $73.3 \%$ males as sufferer and in his study mean affected age group was $15.7 \pm 6.8$ years (study population of age 6.5 years to 29 years). ${ }^{18}$

In our study $80 \%$ patients were on $35-40 \mathrm{mg} / \mathrm{kg}$ daily dose of deferasirox. Mean dose used for iron chelation is to be $38 \mathrm{mg} / \mathrm{kg}$. Reports of Cappellini MD et al suggested mean deferasirox dose $21.6 \pm 6.4 \mathrm{mg} / \mathrm{kg}$ for iron chelation. ${ }^{19}$ Similar study of Merchant $\mathrm{R}$ et al used $33 \mathrm{mg} / \mathrm{kg}$ as for iron chelation and 4 patients needed $35 \mathrm{mg} / \mathrm{kg}$ dose. ${ }^{18}$ In our study only 2 cases (4.4\% cases) had elevated of ALT levels twice above normal levels needing dose reduction this indicates that deferasirox is well tolerated by Indian population. Similarly Cappellini MD et al observed $1 \%$ above stated case. ${ }^{19}$

In our study only 1 case $(2.2 \%)$ had elevated of serum creatinine levels twice above normal levels needing dose reduction this indicates that deferasirox is well tolerated by Indian population. Similarly Cappellini MD, et al observed $8.8 \%$ such cases and Merchant R et al observed $0 \%$ such cases. ${ }^{18-19}$
In our study dose reduction was done in $2.2 \%(\mathrm{n}=1)$ cases due to rapid fall in serum ferritin level.

In our study no adverse reaction like GI upset, rashes were seen. Cappellini MD, et al observed increased adverse events like GI upset, rashes with doses 20-35 $\mathrm{mg} / \mathrm{kg}$ these events subsides after temporary cessation of chelation therapy. ${ }^{19}$ Merchant $\mathrm{R}$ et al reported very mild adverse events needing temporary cessation of chelation therapy. ${ }^{18}$

\section{CONCLUSION}

In conclusion, we state that our findings underline the importance of regular monitoring of serum creatinine, alanine aminotransferase level (SGPT), urine albumin levels in thalassemia patients treated with deferasirox. Dose reduction should be done if any side effect noted or if serum ferritin fall below $500 \mathrm{ng} / \mathrm{ml}$. Dose reduction of therapy done or treatment is halted for 15 day if serum creatinine level increase to $33 \%$ of normal at two consecutive visits or if SGPT level rise 5 times of upper limit of normal at two consecutive visits or if $3+$ albuminuria starts in a normal person. Iron chelation therapy and regular monitoring of serum creatinine, alanine aminotransferase level (SGPT), urine albumin levels if done concurrently with blood transfusion decrease the risk of morbidity and mortality due to iron overload in thalassemia. Deferasirox monotherapy has a good safety profile in pediatric age group. Our results should serve as a benchmark for using DFX chelation therapy in heavily iron overloaded Indian thalassemia major children.

\section{ACKNOWLEDGEMENTS}

The Authors would like to thank Dr. Vikas Goel, Hematologistl, Sanjeevni hospital, for guidance. To $\mathrm{Mr}$ Durgadas Madnani, director of thalassemia society Raipur, India. And also to Mrs. Preeti singh pharmacovigilance technical associate, Seniors Dr. Usha joshi, Dr. Manju Agarwal, Dr.Ajay Halwai, M.D Students, Dr. Lopamudra Kirtania, Dr. Kavita Das, Dr. Anuja Jha, Pt. JNM Medical College Raipur, India.

\section{Funding: No funding sources \\ Conflict of interest: None declared}

Ethical approval: The study was approved by the Institutional Ethics Committee

\section{REFERENCES}

1. John CW. Diagnosis and management of transfusion iron overload; the role of imaging. Am J Hematol. 2007;82(12):1132-5.

2. Hershko CM, Link GM, Konijn AM, Cabantchik ZI. Iron chelation therapy. Curr Hematol Rep. 2005;4:110-1. 
3. Cohen AR, Galanello R, Piga A. Safety and effectiveness of long-term therapy with the oral iron chelatordeferiprone. Blood. 2003;102:1583-7.

4. EMEA: Deferiprone Summary of Product Characteristics. 2006. Available at http://www.ferriprox.com. Accesssed 19 March 2016.

5. Hoffbrand AV, Cohen A, Hershko C. Role of deferiprone in chelation therapy for transfusional iron overload. Blood. 2003;102:17-24.

6. Vichinsky E, Onyekwere O, Porter J. A randomized comparison of deferasirox versus deferoxamine for the treatment of transfusional iron overload in sickle cell disease. Br J Haematol. 2007;136:501-8.

7. Cappellini MD, Cohen A, Piga A. A phase III study of deferasirox (ICL670), a once-daily oral iron chelator, in patients with $\beta$-thalassemia. Blood. 2006;107:3455-62.

8. Cazzola M, Gattermann N, Greenberg P. ICL670, a once-daily iron chelator, is effective and well tolerated in patients with myelodysplastic syndrome (MDS) and iron overload. Haematologica. 2005;90(2):306.

9. Daar S, Taher A, Pathare A. Deferasirox (Exjade, ICL670) provides 24 hour protection from labile plasma iron (LPI), in iron overloaded betathalassaemia patients previously chelated with mono- or combination therapy. Haematologica. 2006;91(1):31.

10. Cabantchik ZI, Breuer W, Zanninelli G, Cianciulli P. LPI-labile plasma iron in iron overload. Best Pract Res Clin Haematol. 2005;18:277-87.

11. Taher A, Jefri A, Elalfy MS, Al Zir K, Daar S, Rofail D, et al. Improved treatment satisfaction and convenience with Deferasirox in iron-overloaded patients with $\beta$ thalassemia results from the escalator trial. Acta Haematol. 2010;123:220-5.

12. EXJADE, (Deferasirox). NDA 21-882 / S-002. (INTERNET). [Revised; 2007]. Available at: http://www.accessdata.fda.gov/drugsatfda_docs/labe 1/2007/021882s002lbl. Accessed 19 April 2016.

13. Olivieri NF, Brittenham GM. Iron-chelating therapy and the treatment of thalassemia. Blood. 1997;89(3):739-61.

14. Ehlers KH, Giardina PJ, Lesser ML, Engle MA, Hilgartner MW. Prolonged survival in patients with $\beta$-thalassemia major treated with deferoxamine. J Pediatr. 1991;118(4):540-5.

15. Hershko C. Oral iron chelators: new opportunities and new dilemmas. Haematologica. 2006;91:130712.

16. Modell B, Khan M, Darlison M. Survival in $\beta$ thalassaemia major in the UK: data from the UK thalassaemia register. Lancet. 2000;355:2051-2.

17. Zurlo MG, Stefano DP, Borgna PC, Palma DA, Piga A, Melevendi C, Gregorio DF. Survival and causes of death in thalassaemia major. Lancet. 1989;2:2730.

18. Merchant R, Ahmed J, Krishnan P, Jankharia B. Efficacy and safety of deferasirox for reducing total body and cardiac iron in thalassemia. Indian Pedia. 2012;49:281-5.

19. Cappellini MD, Bejaoui M, Agaoglu L, Canatan D, Capra M, Cohen A et al. Iron chelation with deferasirox in adult and pediatric patients with thalassemia major. Blood. J Hematol. 2011;118:88493.

Cite this article as: Jaiswal $\mathrm{S}$, Hishikar R, Maheshwari B, Khandwal O, Sheohare R. Safety of deferasirox as an oral iron chelator in thalassemic children. Int J Basic Clin Pharmacol 2016;5:647-50. 